\title{
Correction to: Effect of Silicon Doping on the Electrical Performance of Amorphous SilnZnO Thin-film Transistors
}

\author{
Byeong Hyeon Lee ${ }^{1} \cdot$ Dae-Hwan Kim ${ }^{3} \cdot$ Doo-Yong Lee $^{4} \cdot$ Sungkyun Park ${ }^{4} \cdot$ Sangsig Kim ${ }^{1} \cdot$ Hyuck-In Kwon $^{3}$. \\ Sang Yeol Lee ${ }^{2}$ (1)
}

Published online: 22 April 2021

(c) The Korean Institute of Electrical and Electronic Material Engineers 2021

\section{Correction to: \\ Transactions on Electrical and Electronic Materials (2021) 22:133-139 \\ https://doi.org/10.1007/s42341-021-00285-5}

Unfortunately, the original publication of the article was published without keywords. The keywords are given in this correction.

\section{Keywords}

Thin-Film transistor

Silicon doping

Low-frequency noise

X-ray photoelectron spectroscopy

The original article has been corrected.
Publisher's Note Springer Nature remains neutral with regard to jurisdictional claims in published maps and institutional affiliations.

The original article can be found online at https://doi.org/10.1007/ s42341-021-00285-5.

Sang Yeol Lee

sylee2020@gachon.ac.kr

1 Department of Microdevice Engineering, Korea University, Seoul 136-701, South Korea

2 Department of Electronic Engineering, Gachon University, Seongnam 13120, South Korea

3 School of Electrical and Electronics Engineering, Chung-Ang University, Seoul 156-756, South Korea

4 Department of Physics, Pusan National University, Busan 609-735, South Korea 